(C) 1982. The Genetical Society of Great Britain

\title{
GENOTYPIC FREQUENCIES AT EQUILIBRIUM FOR A MULTILOCUS GAMETOPHYTIC INCOMPATIBILITY SYSTEM
}

\author{
W. E. WEBER, G. WRICKE, and Q. S. TRANG \\ Institut für Angewandte Genetik, Universität Hannover, West Germany \\ Received 23.xi.81
}

\section{SUMMARY}

Equations for the genotypic frequencies at equilibrium in two- and $k$-locus incompatibility systems are given on the basis of an equal fertility of all genotypes. The number of alleles may be different at each locus. The results are compared with those of Charlesworth (1979), who used another approach with unequal fertility.

\section{INTRODUCTION}

IN plants gametophytic incompatibility systems are established in many families. In grasses two loci $S$ and $Z$ act together (Lundqvist, 1956; Hayman, 1956; Lundqvist, 1961; Weimarck, 1968). Under natural conditions the pollen is incompatible with every genotype that can produce gametes with the same alleles as the pollen at both loci. Therefore selfing is excluded, and the progenies consist only of genotypes like $S_{i i} Z_{k l}$ and $S_{i j} Z_{k k}$ (single heterozygotes) or $S_{i i} Z_{k l}$ (double heterozygotes). Homozygous genotypes $S_{i i} Z_{k k}$ do not exist. At equilibrium all alleles at one locus have the same frequency.

Lundqvist (1962) tried to estimate the genotypic frequencies at equilibrium, if there are $n_{1}$ alleles at locus $S$ and $n_{2}$ alleles at locus $Z$. Charlesworth (1979) reexamined this problem and gave quite different formulae. She stated that for her approach a general solution was only possible for $n_{1}=n_{2}=n$. Charlesworth calculated the frequency of a genotype $S_{i i} Z_{k l}$ (and since $n_{1}=n_{2}=n$, the same frequency is given for $S_{i j} Z_{k k}$ ) in the next generation as the sum of all probabilities that a pollen of type $S_{i} Z_{k}$ meets a gamete $S_{i} Z_{l}$ at a compatible genotype, plus the sum of all probabilities, that a pollen of type $S_{i} Z_{l}$ meets a gamete $S_{i} Z_{k}$ at a compatible genotype.

With this approach the probability that a genotype is able to generate a gamete $S_{i} Z_{l}$ and is incompatible to the pollen type $S_{i} Z_{k}$ is larger for the double heterozygotes than for the single heterozygotes. However pollen usually is produced to such an excess, that no difference in fertility between single and double heterozygotes should be expected.

Therefore in this paper another approach is used, which assumes an equal number of progenies for single and double heterozygotes. Then a general solution for arbitrary allele numbers $n_{1}$ and $n_{2}$ can be given. The approach can be extended to more than two loci. 


\section{GENOTYPIC FREQUENCIES AT EQUILIBRIUM FOR TWO LOCI}

To calculate the genotypic frequencies three classes have to be distinguished:

class $X_{1}\left(S_{i i} Z_{k l}\right)$ with frequency $x_{1}$ at equilibrium,

class $X_{2}\left(S_{i j} Z_{k k}\right)$ with frequency $x_{2}$ at equilibrium and

class $X_{3}\left(S_{i j} Z_{k l}\right)$ with frequency $x_{3}$ at equilibrium.

$r_{1}=n_{1} n_{2}\left(n_{2}-1\right) / 2, r_{2}=n_{1} n_{2}\left(n_{1}-1\right) / 2$ and $r_{3}=n_{1} n_{2}\left(n_{1}-1\right)\left(n_{2}-1\right) / 4$ are the numbers of different genotypes in each class. At equilibrium the frequency of each allele at locus $S$ is $1 / n_{1}$ and at locus $Z$ is $1 / n_{2}$. This is also true within the three classes $X_{1}, X_{2}$ and $X_{3}$. A genotype of class $X_{1}$ produces progenies in the relation $\left(n_{2}-2\right) X_{1}:\left(n_{1}-1\right) X_{2}:\left(n_{1}-1\right)$. $\left(n_{2}-1\right) X_{3}$. Similarly the progenies of a genotype from class $X_{2}$ are formed by $\left(n_{2}-1\right) X_{1}:\left(n_{1}-2\right) X_{2}:\left(n_{1}-1\right)\left(n_{2}-1\right) X_{3}$ and progenies of a genotype from class $X_{3}$ by $\left(n_{2}-2\right) X_{1}:\left(n_{1}-2\right) X_{2}:\left(n_{1} n_{2}-n_{1}-n_{2}\right) X_{3}$. Now the genotypic frequencies at equilibrium can be found using the generation matrix $G$, which contains the relative frequencies of the progenies in the different classes:

$$
G=\left[\begin{array}{lll}
\frac{n_{2}-2}{n_{1} n_{2}-2} & \frac{n_{2}-1}{n_{1} n_{2}-2} & \frac{n_{2}-2}{n_{1} n_{2}-4} \\
\frac{n_{1}-1}{n_{1} n_{2}-2} & \frac{n_{1}-2}{n_{1} n_{2}-2} & \frac{n_{1}-2}{n_{1} n_{2}-4} \\
\frac{\left(n_{1}-1\right)\left(n_{2}-1\right)}{n_{1} n_{2}-2} & \frac{\left(n_{1}-1\right)\left(n_{2}-1\right)}{n_{1} n_{2}-2} & \frac{n_{1} n_{2}-n_{1}-n_{2}}{n_{1} n_{2}-4}
\end{array}\right]
$$

At equilibrium $G x=x$ with

$$
x=\left[\begin{array}{l}
x_{1} \\
x_{2} \\
x_{3}
\end{array}\right] .
$$

Only two of the equations are independent. But a third independent equation is given by $x_{1}+x_{2}+x_{3}=1$. The solution is:

$$
\begin{aligned}
& x_{1}=\left(n_{1} n_{2}-n_{1}-2\right)\left(n_{1} n_{2}-2\right)\left(n_{2}-1\right) / Z, \\
& x_{2}=\left(n_{1} n_{2}-n_{2}-2\right)\left(n_{1} n_{2}-2\right)\left(n_{1}-1\right) / Z, \\
& x_{3}=1-x_{1}-x_{2}=\left(n_{1} n_{2}-1\right)\left(n_{1} n_{2}-4\right)\left(n_{1}-1\right)\left(n_{2}-1\right) / Z
\end{aligned}
$$

and

$$
\begin{aligned}
Z= & \left(n_{1} n_{2}-2\right)\left(n_{1}^{2} n_{2}+n_{1} n_{2}^{2}-4 n_{1} n_{2}-n_{1}-n_{2}+4\right) \\
& +\left(n_{1}-1\right)\left(n_{2}-1\right)\left(n_{1} n_{2}-1\right)\left(n_{1} n_{2}-4\right) .
\end{aligned}
$$

In case of $n_{1}=n_{2}=n$ (the case considered by Charlesworth) the formulae are reduced to:

$$
\begin{aligned}
& x_{1}=x_{2}=\left(n^{2}-2\right) / Z, \\
& x_{3}=(n+2)(n-1)^{2} / Z
\end{aligned}
$$


and

$$
Z=2\left(n^{2}-2\right)+(n-1)^{2}(n+2) .
$$

Table 1 contains the frequencies of the three classes at equilibrium. For comparison, the values of Charlesworth are also given for $n_{1}=n_{2}=n$. Though the deviations are small, they are not due to rounding errors, as is shown in the discussion. The case of $n_{1}=n_{2}=2$ is a special case, when double heterozygotes cannot produce progeny (see England, 1974).

\section{MORE THAN TWO LOCI}

In the case of more than two loci the number of equations is increasing. The calculations can be done in a similar way to that described for two loci. In the case of different allele numbers at the loci, the number of classes and therefore the number of equations is $2^{k}-1$. If $n_{1}=n_{2}=\cdots=n_{k}=n>2$, $k$ new classes can be formed, since in this case it is not necessary to distinguish between different types of single heterozygotes or double heterozygotes. The case of $n=2$ at all loci must be excluded, since in this case no seed is set on genotypes heterozygous at all loci. England (1974) gave a general solution for this situation.

First the case of three loci is considered. $X_{001}$ will denote the class of genotypes heterozygous at the third locus only, $X_{010}$ is the class of genotypes heterozygous only at the second locus, $X_{111}$ at all three loci, and so on. $x_{001}, x_{010}, x_{111}$ and so on are the frequencies of the corresponding classes at equilibrium. The equations for $x_{001}, x_{011}$ and $x_{111}$ are given by

$$
\begin{aligned}
x_{001}= & \frac{\left(n_{3}-2\right) x_{001}+\left(n_{3}-1\right)\left(x_{010}+x_{100}\right)}{n_{1} n_{2} n_{3}-2}+\frac{\left(n_{3}-2\right)\left(x_{011} x_{101}\right)+\left(n_{3}-1\right) x_{110}}{n_{1} n_{2} n_{3}-4} \\
& +\frac{\left(n_{3}-2\right) x_{111}}{n_{1} n_{2} n_{3}-8} \\
x_{011}= & \frac{\left(n_{2}-1\right)\left(n_{3}-1\right)\left(x_{001}+x_{010}+x_{100}\right)}{n_{1} n_{2} n_{3}-2} \\
& +\frac{\left(n_{2} n_{3}-n_{2}-n_{3}\right) x_{011}+\left(n_{2}-1\right)\left(n_{3}-1\right)\left(x_{101}+x_{110}\right)}{n_{1} n_{2} n_{3}-4} \\
& +\frac{\left(n_{2} n_{3}-n_{2}-n_{3}\right) x_{111}}{n_{1} n_{2} n_{3}-8} \\
x_{111}= & \frac{\left(n_{1}-1\right)\left(n_{2}-1\right)\left(n_{3}-1\right)\left(x_{001}+x_{010}+x_{100}\right)}{n_{1} n_{2} n_{3}-2} \\
& +\frac{\left(n_{1}-1\right)\left(n_{2}-1\right)\left(n_{3}-1\right)\left(x_{011}+x_{101}+x_{110}\right)}{n_{1} n_{2} n_{3}-4} \\
& +\frac{\left(\left(n_{1}-1\right)\left(n_{2}-1\right)\left(n_{3}-1\right)-1\right) x_{111}}{n_{1} n_{2} n_{3}-8} .
\end{aligned}
$$

In a similar way the equations for $x_{010}, x_{100}, x_{101}$ and $x_{110}$ are constructed. Only six equations are independent. The last equation must be replaced by

$$
x_{001}+x_{010}+x_{100}+x_{011}+x_{101}+x_{110}+x_{111}=1 \text {. }
$$


TABLE 1

Frequency of genotypic classes $\left(\mathrm{x}_{1}, \mathrm{x}_{2}, \mathrm{x}_{3}\right)$ and number of genotypes in each class $\left(\mathrm{r}_{1}, \mathrm{r}_{2}, \mathrm{r}_{3}\right)$ for two loci with $\mathrm{n}_{1}$ and $\mathrm{n}_{2}$ alleles at equilibrium

\begin{tabular}{|c|c|c|c|c|c|c|c|c|c|c|}
\hline \multirow[b]{2}{*}{$n_{1}$} & \multirow[b]{2}{*}{$n_{2}$} & \multicolumn{5}{|c|}{ Single heterozygotes } & \multicolumn{2}{|c|}{$\begin{array}{c}\text { Double } \\
\text { heterozygotes }\end{array}$} & \multirow{2}{*}{\multicolumn{2}{|c|}{$\begin{array}{c}\text { Charlesworth }(1979 \\
\text { single/double } \\
\text { heterozygotes }\end{array}$}} \\
\hline & & $x_{1}$ & $r_{1}$ & $x_{2}$ & $r_{2}$ & $x_{1}+x_{2}$ & $x_{3}$ & $r_{3}$ & & \\
\hline $\begin{array}{l}2 \\
2\end{array}$ & $\begin{array}{l}2 \\
3 \\
4\end{array}$ & $\begin{array}{l}0 \cdot 2500 \\
0 \cdot 4000 \\
0 \cdot 4286\end{array}$ & $\begin{array}{r}2 \\
6 \\
12\end{array}$ & $\begin{array}{l}0 \cdot 2500 \\
0 \cdot 1000 \\
0 \cdot 0714\end{array}$ & 2 & & & $\begin{array}{l}1 \\
3 \\
6\end{array}$ & $\frac{1.500}{-}$ & $\begin{array}{l}\cdot 500 \\
-\end{array}$ \\
\hline $\begin{array}{l}3 \\
3\end{array}$ & $\begin{array}{l}3 \\
4\end{array}$ & $\begin{array}{l}0 \cdot 2059 \\
0 \cdot 2448\end{array}$ & $\begin{array}{r}9 \\
18\end{array}$ & & $\begin{array}{r}9 \\
12\end{array}$ & & & $\begin{array}{r}9 \\
18\end{array}$ & 0.414 & $\begin{array}{c}0.586 \\
-\end{array}$ \\
\hline 4 & $\begin{array}{r}4 \\
5 \\
6 \\
8 \\
10\end{array}$ & $\begin{array}{l}0 \cdot 1269 \\
0 \cdot 1010 \\
0.0839\end{array}$ & $\begin{array}{r}24 \\
50 \\
90 \\
224 \\
450\end{array}$ & $\begin{array}{l}0.1707 \\
0.1456 \\
0.1269 \\
0.1010 \\
0.0839\end{array}$ & $\begin{array}{r}24 \\
50 \\
90 \\
224 \\
450\end{array}$ & $\begin{array}{l}0.3415 \\
0.2911 \\
0 \cdot 2537 \\
0 \cdot 2020 \\
0 \cdot 1678\end{array}$ & $\begin{array}{l}0.6585 \\
0.7089 \\
0.7463 \\
0.7981 \\
0.8322\end{array}$ & $\begin{array}{r}36 \\
100 \\
225 \\
784 \\
2025\end{array}$ & $\begin{array}{l}0 \cdot 202 \\
0 \cdot 168\end{array}$ & $\begin{array}{l}0.657 \\
0.708 \\
0.747 \\
0.798 \\
0.833\end{array}$ \\
\hline
\end{tabular}

In case of $n_{1}=n_{2}=n_{3}$ the number of different equations is reduced to three.

For $k$ loci only the case of $n_{1}=n_{2}=\cdots=n_{k}=n>2$ is considered in more detail. The frequency of a genotype from class $X_{k-m, m}$, heterozygous at $m$ loci and homozygous at $(k-m)$ loci is denoted by $x_{k-m, m}$. At equilibrium this frequency is

$$
x_{k-m, m}=\left(\begin{array}{l}
k \\
m
\end{array}\right) \sum_{l=1}^{k} \frac{\left(\begin{array}{l}
k \\
l
\end{array}\right)(n-1)^{m}-\left(\begin{array}{l}
k-m \\
l-m
\end{array}\right)}{\left(n^{k}-2^{l}\right)\left(\begin{array}{l}
k \\
l
\end{array}\right)} x_{k-l, l}
$$

$\left(\begin{array}{c}k-m \\ l-m\end{array}\right)$ is zero for $l<m$. Table 2 contains the genotypic frequencies for two, three and four loci and 5,10,15 and 20 alleles at each locus.

\section{Discussion}

Under natural conditions no genotypes exist that are homozygous at all incompatibility loci, since pollen grains are not compatible if they carry only alleles also present on the female. Charlesworth $\left(19^{\prime} ; 9\right)$ calculated the

TABLE 2

Frequency of genotypic classes for $\mathrm{n}$ alleles at each locus at equilibrium

\begin{tabular}{|c|c|c|c|c|c|}
\hline \multirow{2}{*}{$\begin{array}{c}\text { No. of } \\
\text { loci }\end{array}$} & \multirow{2}{*}{$\begin{array}{l}\text { Genotypic } \\
\text { class }\end{array}$} & \multicolumn{4}{|c|}{ Frequency at equilibrium } \\
\hline & & $n=5$ & $n=10$ & $n=15$ & $n=20$ \\
\hline 2 & $\begin{array}{l}\text { ho.het }=X_{1,1} \\
\text { het.het }=X_{0,2}\end{array}$ & $\begin{array}{l}0.2911 \\
0.7089\end{array}$ & $\begin{array}{l}0 \cdot 1678 \\
0.8322\end{array}$ & $\begin{array}{l}0.1181 \\
0.8819\end{array}$ & $\begin{array}{l}0.0911 \\
0.9089\end{array}$ \\
\hline 3 & $\begin{array}{l}\text { ho.ho.het }=X_{2,1} \\
\text { ho.het.het }=X_{1,2} \\
\text { het.het.het }=X_{0,3}\end{array}$ & $\begin{array}{l}0.0801 \\
0 \cdot 3865 \\
0.5333\end{array}$ & $\begin{array}{l}0.0245 \\
0.2422 \\
0.7333\end{array}$ & $\begin{array}{l}0 \cdot 0116 \\
0 \cdot 1738 \\
0 \cdot 8145\end{array}$ & $\begin{array}{l}0 \cdot 0068 \\
0 \cdot 1352 \\
0 \cdot 8581\end{array}$ \\
\hline 4 & $\begin{array}{l}\text { ho.ho.ho.het }=X_{3,1} \\
\text { ho.ho.het.het. }=X_{2.2} \\
\text { ho.het.het.het }=X_{1,3} \\
\text { het.het.het.het }=X_{0,4}\end{array}$ & $\begin{array}{l}0.0208 \\
0 \cdot 1499 \\
0.4133 \\
0.4160\end{array}$ & $\begin{array}{l}0.0032 \\
0.0482 \\
0.2917 \\
0.6569\end{array}$ & $\begin{array}{l}0 \cdot 0010 \\
0 \cdot 0231 \\
0 \cdot 2168 \\
0 \cdot 7590\end{array}$ & $\begin{array}{l}0 \cdot 0005 \\
0 \cdot 0135 \\
0 \cdot 1715 \\
0.8146\end{array}$ \\
\hline
\end{tabular}


probability at equilibrium, that a genotype is compatible with a certain pollen type. Since the double heterozygotes are incompatible with four and the single heterozygotes only with two pollen types, her approach is based on the assumption that the stronger selection between pollen types by the double heterozygotes results in a reduced seed set. The percentage of reduction depends on the number of alleles.

Observations on the pollen tube growth in rye indicate that pollen is in excess and several pollen tubes can start to grow. Therefore it seems an unjustified assumption that the seed set of the double heterozygotes is reduced. If the fertility of all types is equal, a general solution can be given for arbitrary numbers $n_{1}$ and $n_{2}$ of alleles, as was shown in this paper.

In case of $n_{1}=n_{2}=n$, the deviations from the result of Charlesworth (1979) are small and practically disappear, provided $n$ is large. For large $n$ the differences in fertility are small in the approach of Charlesworth.

In the general case of $k$ loci, the number of equations increases rapidly as $k$ exceeds 2 . In the literature, few species with more than two incompatibility loci are known. Till now the highest number of loci has been found in Beta vulgaris. Experimental results led to the ass umption (Larsen, 1977), that at least four incompatibility loci are involved. Further loci, which are homozygous in his material, cannot be excluded.

The expected genotypic frequency at equilibrium must be known, if the number of alleles at the incompatibility loci is to be estimated experimentally. Experimental results on this topic for rye will be given by us in a future paper.

\section{REFERENCES}

CHARLESWORTH, D. 1979. Some properties of populations with multilocus homomorphic gametophytic incompatibility systems. Heredity, 43, 19-25.

ENGLAND, F. J. W. 1974. The use of incompatibility for the production of $F_{1}$ hybrids in forage grasses. Hereaity, 32, 183-188.

HA YMAN, D. L. 1956. The genetical control of incompatibility in Phalaris coerulescens Desf. Austr. J. Biol. Sci., 9, 321-331.

LARSEN, K. 1977. Self incompatibjlity in Beta vulgaris $L$. I. Four gametophytic, complementary $S$-loci in sugar beet. Hereditas, 85, 227-248.

LUNDOVIST, A. 1956. Self incompatibility in rye. Hereditas, 42, 293-348.

LUNDOVIST, A. 1961. Self incompatibility in Festuca pratensis Huds. Hereditas, 47, 542-562.

LUNDOVIST, A. 1962. The nature of two-loci incompatiblity systems in grasses. II. Number of alleles at the incompatibility loci in Festuca pratensis Huds. Hereditas, 48, 169-181. WEIMARCK, H. 1968. Self incompatibility in the grasses. Hereditas, 60, 157-166. 